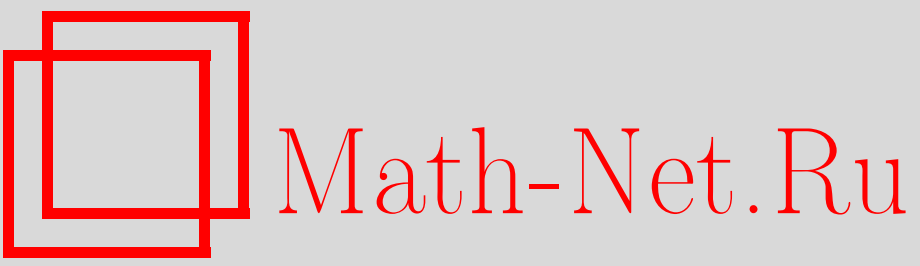

Инструкция для авторов, ТМФ, 2001, том 126, номер 3, 489-496

DOI: https://doi.org/10.4213/tmf444

Использование Общероссийского математического портала Math-Net.Ru подразумевает, что вы прочитали и согласны с пользовательским соглашением

http://www.mathnet.ru/rus/agreement

Параметры загрузки:

IP : 35.173 .219 .149

26 апреля 2023 г., 16:45:22 


\author{
ТЕОРЕТИЧЕСКАЯ \\ И МАТЕМАТИЧЕСКАЯ \\ ФИЗИКА \\ Том 126, Ђ 3 \\ март, 2001
}

(c) 2001 г.

\title{
ИНСТРУКЦИЯ ДЛЯ АВТОРОВ
}

\section{1. ОБШИЕ ПОЛОЖЕНИЯ}

1.1. Журнал посвяшен фундаментальным проблемам теоретической и математической физики и публикует работы по следуюшим темам:

- математические проблемы квантовой механики;

- квантовая теория поля и математические аспекты теории элементарных частищ;

- квантовая теория рассеяния, метод обратной задачи;

- математические проблемы статистической физики;

- гравитация, калибровочные поля, теория струн и мембран;

- суперсимметрии;

• вполне интегрируемые и родственные им классические и квантовые модели;

- алгебраические, геометрические и другие математические методы современной теоретической физики.

Работы феноменологического и чисто вычислительного характера не публикуются.

1.2. Журнал публикует оригинальные научные статьи объемом до 15 журнальных (20 машинописных) страниц и обзорные статьи, написанные по заказу Редколлегии. Возможна также публикация трудов конференций (см. п. 1.11).

1.3. Редколлегия приглашает своих авторов к сотрудничеству в публикации заказных статей. Мотивированные предложения авторов будут рассматриваться Редколлегией.

1.4. Ж Журнал издается в двух версиях: оригинальное русское издание ("Теоретическая и математическая физика") и его перевод на английский язык ("Theoretical and Mathematical Physics"). Перевод журнала и распространение английской версии осуществляет Plenum Publishing Co.

1.5. Представление рукописи в журнал предполагает, что изложенные в ней результаты не публиковались ранее (кроме как в форме тезисов, кратких сообщений или 
лекций), что эти результаты не составляют содержание иной статьи, направленной в другой журнал, что публикация этих результатов одобрена всеми соавторами, если таковые имеются, и что публикация статьи не вызовет законных возражений со стороны учреждений, где была выполнена работа. Ответственность за соблюдение вышеперечисленных условий возлагается на авторов. Представлять по данному поводу в журнал какие-либо письма, акты, справки и т.п. не требуется.

1.6. Представленные статьи и авторефераты рецензируются и рассматриваются на заседании Редколлегии. Критериями отбора являются соответствие профилю журнала, новизна, актуальность и обоснованность результатов. Необходимые условия - доступность и ясность изложения. Решение Редколлегии сообщается авторам. В случае, если статья не принимается к публикации, авторы получают мотивированное уведомление, причем Редколлегия не считает своей непременной обязанностью вступать в полемику с авторами. Рукописи авторам не возврашаются.

1.7. K рассмотрению принимаются статьи, написанные на русском или английском языке. Статьи, представленные на английском языке и принятые к публикации, переводятся на русский язык для опубликования в русской версии журнала.

1.8. Принятые к публикации статьи редактируются. Редакция, как правило, согласовывает правку, выходящую за пределы чисто грамматической, с авторами. Редакция не имеет возможности высылать авторам корректуру.

1.9. Представление рукописи в журнал в случае принятия ее в печать означает, что авторы поручают Редколлегии представлять их интересы при решении всех вопросов, связанных с использованием опубликованной статьи: ее копированием и воспроизведением в любой форме, включая перевод на другой язык и публикацию этого перевода.

1.10. Издатель русской версии не выплачивает гонорары за опубликованные статьи, за исключением отдельных статей, написанных по заказу Редколлегии. Гонорар за право перевода статей, представленных и опубликованных на русском языке, выплачивается издателем английской версии Plenum Publishing Co (подробности см. в Приложении А).

1.11. Решение о публикации материалов конференций принимается на заседании Редколлегии по представлению Оргкомитета. При этом выполнение рецензирования и других условий п. 1.6 обеспечивается специальным договором между Редколлегией и Оргкомитетом.

1.12. Авторам высылаются 5 оттисков русской и 10 оттисков английской версий статей.

\section{2. ТРЕБОВАНИЯ К ПРЕДСТАВЛЯЕМЫМ СТАТЬЯМ}

2.1. Статья представляется в Редакцию в двух экземплярах, оформленных в соответствии с разделом 3. Статья должна быть подписана авторами с резолюцией "в печать". 
2.2. Статья, как правило, должна быть подготовлена в одном из стандартных форматов $\mathrm{T}_{\mathrm{E}} \mathrm{X}$. В виде исключения принимаются статьи, подготовленные на пишушей машинке или с помошью текстового редактора с последуюшим вписыванием формул от руки (правила разметки формул см. в п. 3.4). Использование для написания формул каких-либо программных средств, кроме версий $\mathrm{T}_{\mathrm{E}} \mathrm{X}$ 'а, а также впечатывание отдельных частей формул на машинке не допускается.

2.3. В статье не должно быть ссылок на неопубликованные работы, результаты которых используются в доказательствах.

2.4. На отдельных листах прилагаются:

- сведения о каждом из авторов, включающие: имя, отчество, фамилию (в точности соответствующие паспортным данным), полное название учреждения, почтовый адрес с индексом почтового отделения, номер телефона с кодом города, адрес электронной почты, а также адрес для научных контактов, предназначенный для публикации в журнале (необходимо указать автора, ответственного за переписку с редакцией);

- аннотация (с названием статьи, инициалами и фамилиями авторов)

- список ключевых слов.

2.5. Редколлегия убедительно просит:

- представлять английские версии указанных в п. 2.4 сведений;

- указывать принятые в западной литературе написания инициалов и фамилий авторов статьи, а также написания всех других инициалов и фамилий, упоминаемых в статье, включая список литературы;

- при транслитерации русских фамилий пользоваться таблицей, данной в Приложении Б.

\section{3. ПРАВИЛА ОФОРМЛЕНИЯ РУКОПИСЕЙ}

Выполнение перечисленных ниже правил может заметно ускорить публикацию статьи.

\section{1. Общие замечания:}

- на первой странице помещаются инициалы и фамилии авторов, название статьи, аннотация, далее - основной текст;

- нумерация формул осуществляется последовательно по всей статье либо последовательно внутри каждого раздела (двойная нумерация); аналогично нумеруются теоремы, леммы и т.п.;

- нумеруемые формулы обязательно выделяются в отдельную строку;

- подстрочные примечания в тексте нумеруются последовательно по всей статье арабскими цифрами со скобкой; 
- просьба благодарности и ссылки на финансовую поддержку помешать в конце статьи перед списком литературы;

- ссылки на литературу нумеруются последовательно по всей статье арабскими цифрами в квадратных скобках на строке (правила оформления см. в разделе 4).

\section{2. Правила оформления рисунков:}

- рисунки прилагаются на отдельных листах (в двух экземплярах);

- на обороте рисунков указываются фамилии авторов и номер рисунка;

- место рисунка должно быть указано простым карандашом на полях в том месте, где он первый раз упоминается в тексте;

- на рабочем поле рисунка следует использовать минимальное количество буквенных и цифровых обозначений;

- в случае, если все объекты, изображенные на рисунке, могут быть заданы аналитически в декартовой и/или полярной системах координат, рекомендуется представлять на отдельных листах “Функциональное описание рисунков" (это заметно повысит качество печати рисунков);

- принимаются рисунки, выполненные на лазерном или матричном принтере, если выдержана нужная интенсивность и толщина линий.

\section{3. Для статей, набранньх на компьютере:}

В настоящее время оригинал-макет журнала готовится на компьютере при помощи издательского пакета $\mathrm{T}_{\mathrm{E}} \mathrm{X}$. Авторы, пользующиеся диалектами этого пакета $\left(\mathrm{AmST}_{\mathrm{E}} \mathrm{X}, \mathrm{L}_{\mathrm{E}} \mathrm{X} 2.09, \mathrm{~L}_{\mathrm{E}} \mathrm{X} 2 \varepsilon\right)$, должны иметь в виду следуюшее:

- при наборе текста следует руководствоваться правилами, изложенными в стандартных пособиях, например:

М. Спивак. Восхитительный ТЕХ. М.: Мир, 1993,

с ориентацией на стиль amsppt.sty, a также

C. М. Львовский. Набор и верстка в пакетах $\mathrm{L}^{\mathrm{A}} \mathrm{T} \mathrm{X}, 2$ 2-е изд. М.: Космосинформ, 1995;

- статья должна быть напечатана на одной стороне листа формата А4 шрифтом размера 12 pt, расстояние между строками должно быть $24 \mathrm{pt}$, при этом ширина страницы 160 мм, высота 230 мм (в строке примерно 80 знаков); 
- для ускорения прохождения статьи и уменьшения вероятности опечаток желательно вместе со статьей сдать в Редакцию соответствуюший файл, который может быть прислан по электронной почте; адрес Редакции:

tmph@mi.ras.ru;

- файл не должен содержать отличий от представленного к публикации текста статьи (именно последний, а не электронная версия, считается официально поданным в печать);

- разметка статей, набранных в ТЕХ'е, не требуется;

- рисунки также желательно представлять в электронном виде в одном из стандартных векторных или растровых форматов: PCX, EPS, TIFF, GIF; предпочтительно вьполнять рисунки с разрешением $600 \mathrm{dpi}$.

В Редакции имеются подробные инструкции по подготовке файлов. Они выдаются или высылаются по просьбе авторов.

3.4. Для статей, напечатанных на пишущей машинке:

- работа должны быть напечатана крупным стандартным шрифртом на одной стороне белого листа формата А4 через два интервала с широкими (4 см) полями слева и сверху;

- на странице должно быть не более 30 строк по 60-65 знаков в строке:

- в тексте нельзя делать рукописные вставки и вклейки;

- все формулы, а также математические символы в тексте должны быть вписаны четко, свободно и крупно (размер строчных букв не менее 6 мм, прописных - не менее 8 мм, индексов - не менее 3 мм);

- прописные (заглавные) и строчные буквы, имеюшие одинаковые начертания, следует разметить простым карандашом (прописные подчеркнуть двумя чертами снизу, а строчные двумя чертами сверху); все греческие буквы подчеркиваются одной чертой снизу красным карандашом; все готические буквы обводятся синим карандашом (в кружок), а рукописные латинские прописные - желтым (в кружок);

- надстрочные индексы и показатели степени отмечают простым карандашом знаком повышения $\cup$, а подстрочные индексы - знаком понижения $\cap$ (подчиненные индексы, т.е. индексы индексов отмечаются соответственно вторыми знаками повышения или понижения);

- математические символы типа $\lim , \log , \max , \sin , \operatorname{Im}$ и т.п. и число 0 отмечаются карандашом прямой скобкой снизу. Буква “O” в отличие от нуля подчеркивается волнистой чертой. Для обозначения вещественной прямой и комплексной плоскости рекомендуется использовать соответственно буквы $\mathbb{R}$ и $\mathbb{C}$ “ажурного шрифта";

- должны различаться по написанию $J$ ( “йот"), I ("и”), единица, | - вертикальная черта, штрих и запятая в индексах, необходимо делать четкое различие в 
написании $e$ ( "е") и $l$ ( “эль”); в случае, если написание может вызвать сомнение, просим авторов дать на полях пояснение неясной буквы по-русски карандашом, например $\xi-$ кси, $\zeta$ - дзета и т.д. Знаки суммирования и произведения (в отличие от греческих букв $\Sigma$ и П) не подчеркиваются красным;

- волнистой чертой подчеркиваются формулировки теорем, лемм и следствий (кроме формул и их номеров);

- окончание формулировки утверждения, замечания, примера и т.п., а также окончание доказательства отмечаются квадратиком $\square$.

\section{4. ОФОРМЛЕНИЕ БИБЛИОГРАФИЧЕСКИХ ССЫЛОК}

В настоящее время издатели как русской, так и английской версий повышают требования к оформлению библиографических ссылок, что связано с включением публикуемых статей в различные базы данных. Поэтому Редколлегия убедительно просит авторов в каждой ссылке, помимо инициалов и фамилий авторов (инициалы перед фамилией), указьвать следующие данные:

- по журнальным статьям: название журнала, год издания, том, выпуск (не обязателен, если нумерация страниц в данном журнале последовательная внутри тома) и первая страница;

- по статьям, направленным в печать: название статьи, название журнала и год представления;

- по препринтам: название, номер препринта, город, институт (университет), опубликовавший препринт, и год публикации;

- по статьям, направленным в hep-th или другую электронную базу данных: название статьи, название базы данных и регистрационньй номер по базе, год представления;

- по статьям в сборниках и книгах: название статьи, номер первой страницы, полная книжная ссылка (а именно: название книги или сборника; номер тома и его название, если таковые имеются; инициалы и фамилия редактора (редакторов); издательство, город и год публикации);

- по книгам: название, номер тома и его название (если таковые имеются), город, издательство, год публикации;

- по сборникам: помимо полной книжной ссылки, следует также указывать инициалы и фамилию редактора (редакторов);

- по диссертациям: название работы, ученая степень, город, институт (университет) и год зашиты;

- по частным сообщениям: год.

Редколлегия будет благодарна авторам также за предоставление следующих сведений: 
- при ссылке на переводное (на русский язык) издание (книгу) - полная ссылка на оригинальное издание на одном из европейских языков;

- при цитировании статей, вышедших в свет на русском языке в русском или советском журнале, - полная ссылка на переводное издание, если таковое существует (обычно при переводе номера страниц изменяются);

- при цитировании книг, впервые вышедших в свет на русском языке, - полная ссылка на перевод (если таковой сушествует и известен автору) данного издания на английский (или другой европейский) язык.

ПРИЛОЖЕНИЕ А

\section{Порядок получения авторского гонорара}

Авторский гонорар за статьи, опубликованные по первое полугодие 1998 г. (т.е. по том 115, вып. 3 включительно), выплачивается через Российское авторское общество (Москва, ул. Б.Бронная, д. 6-а). Для получения этого гонорара авторам необходимо обратиться по указанному адресу с паспортом и списком опубликованных работ. Иногородние авторы могут обратиться в свои местные отделения РАО, а авторы из стран СНГ - в аналогичные организации, сотрудничающие с РАО. С сумм, выплачиваемых РАО, удержан подоходньй налог.

Авторский гонорар за статьи, опубликованные в журнале начиная со второй половины 1998 г. (т.е. с тома 116, вып. 1), переводится на именные счета (открываемые по зачислению) авторов в операционном отделе Тверского отделения № 7982 Московского банка акционерно-коммерческого Сберегательного банка РФ по адресу: 103006, г. Москва, ул. Мал. Дмитровка, д. 15 (ниже ТО). Ориентировочное время поступление гонораров - по прошествии месяца со дня окончания квартала, в котором опубликована статья. Подоходный налог с авторского гонорара не удержан.

Сушествуют три возможности получения авторского гонорара.

- Можно обратиться лично с паспортом по указанному адресу (правый подъезд, окно № 8).

- Можно перевести гонорар в местный банк.

Перевод гонорара граждан Р $\Phi$ может быть осуществлен только в отделение Сбербанка РФ (например, по месту жительства) по форме 143. При заполнении этой формы необходимо указать следуюшие реквизиты ТО:

$\mathrm{P} / \mathrm{c} 30301810338000603804$

БИК 044525342 ИНН 7707083893

кор/с 30101810600000000342

ОПЕРУ ГУЦБ РФ

Вместо номера счета следует указать: счет открыт по зачислению.

Перевод гонорара граждан других стран СНГ может быть осуществлен в Сбербанк Вашей страны или любой другой банк, работаюший с Bank of New York. Для перевода необходимо указать следующие реквизиты ТО: 
Swift: SABRRUMM 100

Bank: Savings Bank of the Russian Federation (Moscow, Savings Bank, Russia)

Отделение: Tverskoe branch 7982, Moscow, Russia

Номер Вашего счета: счет открыт по зачислению

- Гонорар может быть получен другим лищом в ТО по Вашей нотариально заверенной доверенности. Доверенность должна быть составлена на русском языке по следуюшей форме:

\section{ДОВЕРЕННОСТЬ}

Я,.......(фамилия, имя, отчество)...................., проживающий(ая) по адре-

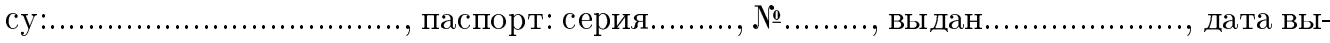
дачи “...”.......... 19..г., доверяю получить причитающийся мне гонорар, находящийся на счете (счетах), открытом (открытых) на мое имя по зачислению в операционном отделе Тверского отделения № 7982 Московского банка акционерно-коммерческого Сберегательного банка РФ, расположенного по адресу: г. Москва, ул. Мал. Дмитровка, д. 15, ..(фамилия, имя, отчество)....................., подпись которого(ой) …......... удостоверяю. Доверенное лицо проживает по адресу:

..............., паспорт: серия........., №........., выдан....................., дата выдачи “..."
$19 . . . .$.

ПРИЛОЖЕНИЕ Б

\section{Британо-американские правила транслитерации:}

\begin{tabular}{|c|c|c|c|}
\hline A & A & $\mathrm{P}$ & $\mathrm{R}$ \\
\hline Б & B & $\mathrm{C}$ & $\mathrm{S}$ \\
\hline B & $\mathrm{V}$ & $\mathrm{T}$ & $\mathrm{T}$ \\
\hline$\Gamma$ & G & $\mathrm{y}$ & $\mathrm{U}$ \\
\hline Д & $\mathrm{D}$ & $\Phi$ & $\mathrm{F}$ \\
\hline $\mathrm{E}$ & $\mathrm{E}$ & $\mathrm{X}$ & $\mathrm{KH}$ \\
\hline$\ddot{\mathrm{E}}$ & $\mathrm{E}$ & Ц & TS \\
\hline K & $\mathrm{ZH}$ & $\Psi$ & $\mathrm{CH}$ \\
\hline 3 & Z & Ш & SH \\
\hline И & I & Ш & $\mathrm{SHCH}$ \\
\hline Й & I & ، & $"$ \\
\hline K & K & Ы & Y \\
\hline Л & $\mathrm{L}$ & b & , \\
\hline M & M & 习 & É \\
\hline $\mathrm{H}$ & $\mathrm{N}$ & Ю & $\mathrm{YU}$ \\
\hline $\mathrm{O}$ & $\mathrm{O}$ & Я & YA \\
\hline$\Pi$ & $\mathrm{P}$ & & \\
\hline
\end{tabular}

Внимание: используйте, пожалуйста, $\bar{Y}$ в комбинациях ЫА и ЫУ, чтобы отличать их от Я и Ю. 